\section{Influence Of The Internal Heat Source On The Temperature Field And Heat Transfer Through Light- Translucent Coating Of Flat Solar Plants}

\section{Usmonov Nizomjon Orifovich}

Phd, Associate Professor, Department Of

"Thermodynamics And Heat Engineering", Tashkent State Technical University, Uzbekistan

Isakhodjaev Khayrulla Sunnatullaevich

Phd, Associate Professor, Department Of

"Thermodynamics And Heat Engineering", Tashkent State Technical University, Uzbekistan
G OPEn ACCess

The American Journal Of Engineering And Technology

JULY 2020

Page No.: 46-50

Volume-II Issue-VII

PUBLISHED: 30 JULY 2020

www.usajournalshub.com/inde

x.php/tajet

Copyright: Original content from this work may be used under the terms of the Creative Commons Attribution 4.0 licence.

\title{
Abstract:
}

The results of research on the calculation of the temperature field and heat fluxes through the translucent coatings of flat solar installations and the proposal of appropriate expressions for determining their values are presented.

Keywords: solar radiation, translucent coating, heat.

\section{Introduction}

Flat solar installations (solar water and air heating collectors) are the most common typical technical means for converting solar energy into low-potential heat, which can be used to fully or partially cover the heat needs of heat consumers of the same temperature potential. 
The role of the translucent coating is to create and enhance the greenhouse effect inside the collector housing, to prevent the access of solar radiation to the front surface of the blackened plate as little as possible and to minimize the radiant heat losses of the latter. The heat-insulated bottom and side walls of the housing reduce conductive-convective heat losses of the plate to the environment.

\section{THE MAIN FINDINGA AND RESULTS}

The physical picture of the processes of formation of the temperature field and heat transfer through the translucent coatings of flat solar installations are somewhat different than that of traditional flat walls, which is widely covered in the courses on heat transfer [1, $1975 ; 3]$. So, as a result of partial absorption and conversion into heat of solar radiation passing through the translucent coatings in the latter, an internal heat source is formed, the power of which depends on the optical properties of the translucent coating material and the surface density of the solar radiation flux incident on its front surface.

A flat solar thermal collector consists of a blackened plate (solar radiation receiver), placed in a flat box (housing) with a heat-insulated bottom and side walls, top coverings with a translucent material (for example, window glass) (Fig. 1).

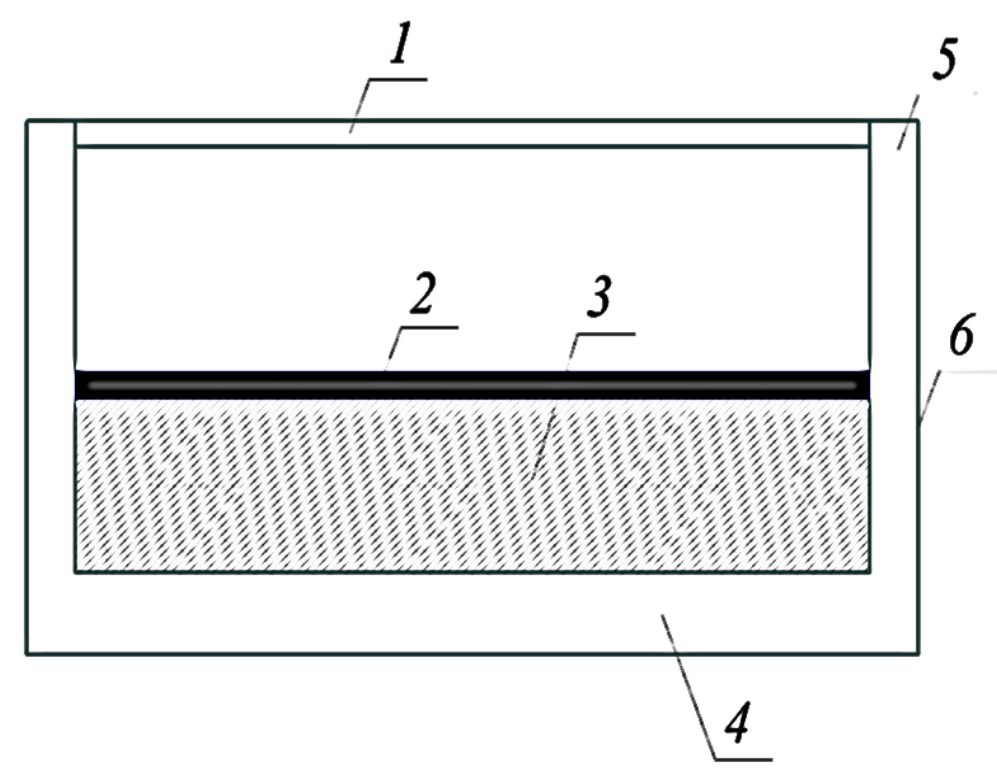

Figure 1. Schematic diagram of a flat solar thermal collector: 1 - translucent coating; 2 - blackened plate; 3 - bottom insulation; 4 - bottom; 5 - side walls; 6 - case. 


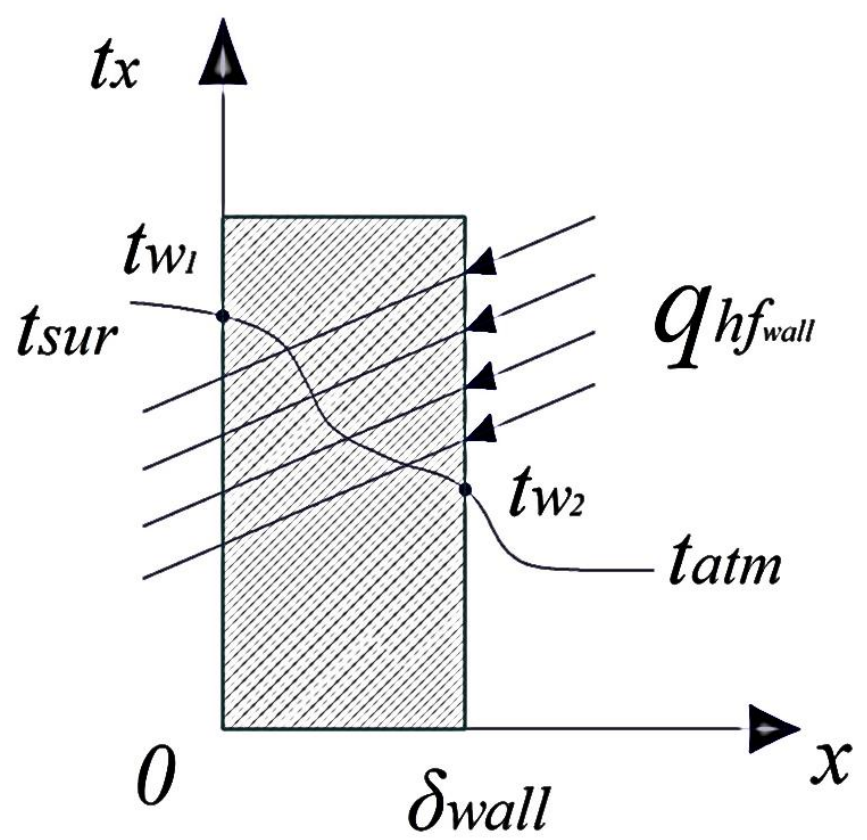

Fig. 2. Calculated thermal scheme for choosing the boundary conditions for equation (1): $t_{\text {sur }}$ and $t_{a t m}$ - respectively, the temperatures of the front surface of the blackened plate and the environment.

In the blackened plate, the energy of solar radiation is absorbed and converted into heat, which has passed through the translucent coating of the collector body.

The presence of an internal heat source in the translucent coatings of the housing of flat solar installations, as a rule, leads to an increase in their temperature, which, to a certain extent, is an obstacle to heat losses of the blackened plate through the coating under consideration.

To determine the degree of influence of an internal heat source formed as a result of partial absorption and conversion into heat passing through translucent coatings on the temperature field and heat transfer through them, we use the solution of the onedimensional differential equation of second-order stationary heat conductivity in the presence of an internal heat source in them, the power of which is exponentially distributed by their thickness $[4,2008]$

$$
\frac{d^{2} t x}{d x^{2}}-\frac{1-\rho_{w}}{(\delta \lambda)_{w}} \cdot\left\{1-e^{\frac{-[\beta \cdot(\delta-x)] w}{\cos r}}\right\} \cdot q_{h f_{w}}=0,
$$

where $\rho_{w}, \delta_{w}$ and $\lambda_{w}$ - respectively, the reflectance of solar radiation, thickness and thermal conductivity of the material of the translucent coating; $\beta_{w^{-}}$coefficient of extinction (attenuation) of the material of the translucent coating of the transmitted solar radiation; $r$ - is the angle of refraction of solar radiation when passing through the translucent coating; $q_{h f_{w}}$ is the surface density of the solar radiation flux falling on the front surface of the translucent coating. 
The boundary conditions for equation (1), in accordance with Figure 2, are

$$
\left\{\begin{array}{cc}
t_{x}=t_{w_{1}} & \text { при } x=0 \\
t_{x}=t_{w_{1}} & \text { при } x=\delta_{w}^{\prime}
\end{array}\right.
$$

where $t_{w_{1}}$ and $t_{w_{2}}$ - are, respectively, the temperatures of the inner (rear) and outer (front) surfaces of the translucent coating under consideration.

Based on the solution of equation (1) under boundary conditions (2), we obtain expressions for calculating the temperature field of a translucent coating in the presence of an internal heat source in it, formed as a result of partial absorption and conversion into heat of solar radiation passing through it, the thermal power of which is exponentially distributed over its thickness is

$t_{x}=t_{w_{1}}-\left\{t_{w_{1}}-t_{w_{2}}-\left[\frac{0,5 \cdot(\delta-x)_{w}}{\lambda_{w}}-\frac{\cos ^{2} r}{\left(\beta^{2} \cdot \delta \lambda\right)_{w}}\left(1-e^{-\frac{(\beta \delta)_{w}}{\cos r_{w}}}\right)\right]\left(1-\rho_{w}\right) q_{h f_{w}}\right\} * \frac{x_{w}}{\delta_{w}}-\frac{\cos ^{2} r}{\left(\beta^{2} \cdot \delta \lambda\right)_{w}} e^{-\frac{(\beta \delta)_{w}}{\cos r_{w}}}(1-$

$\left.e^{-\frac{(\beta \delta)_{w}}{\cos r_{w}}}\right)\left(1-\rho_{w}\right) q_{h f_{w}}$

As follows from the analysis of solution (3), at $x=0, t_{x}=t_{w_{1}}$ and at $x=\delta_{w}$, which fully satisfies the boundary conditions and thereby confirms its reliability.

An expression for calculating the distribution of the surface heat flux density over the thickness of the translucent coating of the collector body $q_{x}$ in the presence of an internal heat source in it, established on the basis of solution (3) and the Fourier law [1, 1975].

$$
q_{x}=-\lambda_{w} \frac{d t_{x}}{d x}
$$

has the form

$q_{x}=\left(t_{w_{1}}-t_{w_{2}}\right) \frac{\lambda_{w}}{\delta_{w}}-\left\{0,5\left(1-\frac{2 x_{w}}{\delta_{w}}\right) \frac{\cos _{w}}{(\beta \delta)_{w}}\left[e^{-\frac{(\beta \delta)_{w}}{\cos r}}-\frac{\cos _{w}}{(\beta \delta)_{w}}\left(1-e^{-\frac{(\beta \delta)_{w}}{\cos r_{w}}}\right)\right]\right\} *\left(1-\rho_{w}\right) q_{h f_{w}}$.

The expression for determining the values of the surface heat flux densities on the internal $q_{x=0}$ and external $\left(q_{x=\delta_{w}}\right)$, obtained on the basis of solution (5) at $x=0$ and $x=\delta_{w}$, respectively, have the form

$q_{x=0}=\left(t_{w_{1}}-t_{w_{2}}\right) \frac{\lambda_{w}}{\delta_{w}}-\left\{\frac{\cos _{w}}{(\beta \delta)_{w}}\left[e^{-\frac{(\beta \delta)_{w}}{\cos r}}-\frac{\cos _{w}}{(\beta \delta)_{w}}\left(1-e^{-\frac{(\beta \delta)_{w}}{\cos r}}\right)+0,5\right]\right\} *\left(1-\rho_{w}\right) q_{h f_{w}}$,

and

$q_{x=\delta}=\left(t_{w_{2}}-t_{w_{1}}\right) \frac{\lambda_{w}}{\delta_{w}}-\left\{\frac{\cos _{w}}{(\beta \delta)_{w}}\left[1-\frac{\cos _{w}}{(\beta \delta)_{w}}\left(1-e^{-\frac{(\beta \delta)_{w}}{\operatorname{cosr}}}\right)-0,5\right]\right\} *\left(1-\rho_{w}\right) q_{h f_{w}}$.

As can be seen from the analysis of solutions (6) and (7), all other things being equal (we mean the values $\rho_{w}, \beta_{w}, \delta_{w}, \lambda_{w}, r_{w}$ and $q_{h f_{w}}$ ) in the presence of an internal heat source 
in the translucent coatings of the body of flat of solar installations, the values $q_{x=0}$ and $q_{x=\delta_{w}}$ are not equal to each other.

Their difference, equal to

$\Delta q_{x}=q_{x=\delta}-q_{x=0}=\left[1-\frac{\operatorname{cosr}_{w}}{(\beta \delta)_{w}}\left(1-e^{-\frac{(\beta \delta)_{w}}{\cos r_{w}}}\right)\right]\left(1-\rho_{w}\right) q_{h f_{w}}$,

is the surface flux density absorbed by the considered translucent coating of solar radiation. Only under the condition $\beta_{w}=0$, which is permissible for a perfectly clean translucent coating, can the power of the internal heat source in it be neglected, and, as follows from solution (8), $q_{x=0}$ and $q_{x=\delta_{w}}$ can be considered.

\section{Conclusion}

1. Calculated expressions are proposed for determining the temperature field and heat transfer through the translucent coatings of flat solar installations in the presence of an internal heat source formed as a result of partial absorption and conversion of solar radiation passing through them into heat, the power of which is exponentially distributed over their thickness.

2. An expression is proposed for calculating the surface density of the solar radiation flux absorbed by the translucent coatings of flat solar installations.

\section{References}

[1]. Isachenko V.P., Osipova V.A., Sukomel A.S. (1975) Heat transfer. - Moscow. "Energy". - p. 488.

[2]. Mikheev M.A. (1956) Heat Transfer Basics. - Leningrad. Gosenergoizdat. - p. 392.

[3]. Cengel Y.A. Heat Transfer. A Practical Approach. Second Edition. McGRAW-HILL. - 932 p.

[4]. Avezov R.R., Avezova N.R., Samiev K.A. (2008) Temperature Field and Heat Flows Through Transparent Covers of Flat-Plate Solar Collector Housings // Applied Solar Energy. - USA. Vol.44, №1. - pp. 13-16.

[5]. Avezov R.R., Avezova N.R., Ruziev O.S., Vakhidov A.U. (2012) Effective reduced coefficient of heat loss of translucent coatings of flat water-heating solar collectors // Heliotekhnika - Tashkent. №. 4. - pp. 12-19 